\title{
AMBIGUOUS PIGS: An Excursion into Porcine Poetics and Prosody · Diane Morgan
}

\author{
This little pig went to market \\ This little pig stayed home \\ This little pig had roast beef \\ This little pig had none \\ And this little pig cried wee, wee, wee, \\ All the way home.
}

THERE IT IS. Deceptively simple, Annie Minnous' great work, the "Little Pig Poem," immortalized on the toes and hearts of untold multitudes, conceals beneath its smooth surface a subtle complexity belied by the lyric purity of its lines. The amphiboly of the title is only a foretaste of the conundrum of the whole.

Historically, of course, its value cannot be measured, for it is perhaps the first piece of literature in the Western World designed for multi-media presentation. This fact alone deserves more that the cursory analysis which has heretofore attended it. Toes are an integral part of this great work, adding not only breadth of vision and a certain architectonic quality, but also a sense of deep personal involvement. Although this facet has long been recognized among critics, its central mystery has been left unplumbed. What is it about toes which gives this poem its joie de vivre, its je ne sais quoi, its peculiar and undeniable charm? It can be seen in a moment that fingers would not do. The poem would grow flat almost at once. Unhappily, an in-depth discussion of this aspect of the poem is beyond the scope of this exegesis. (It deserves a Master's thesis, at the very least. One possible angle of exploring this issue might be the interesting fact that pigs themselves have no toes, but instead a cloven hoof.)

Another facet of the multidimensional quality of this work is that it is inherently communal. The poem, in short, does not "work" when recited alone. The propinquity of a second person is absolutely vital. It is then that the real magic of the verse becomes apparent. No one, it seems, is immune to the essential power of the Little Pig Poem when it is properly presented. It forces a response from even the most toughened critic. 
Yet, ultimately, these qualities are really peripheral to the great work itself. It is immediately apparent, even to the most casual reader, that even stated baldly, coldly, whitely on paper, the Little Pig Poem is indeed monumental. It seethes, nay, boils with understatement, delicious ambiguity, fullness. There is not a superfluous word, yet one is left with the feeling of something said. And how rare a quality is this today. The powerful dactyls, the initial demonstrative adjectives, sweep us at once into a new world, resonant of, no-precisely parallel in its structure, meter, and tone to our great American epic "Evangeline": "This is the Forest Primeval"-"This little pig went to market." From the internal evidence alone is it not practically certain Longfellow had the Little Pig Poem in mind when he set pen to paper?

It is now time to examine the poem carefully. The first question to strike the critic is of course: "How many pigs are there?" The naive reader, perhaps checking his toes for confirmation, will answer, "five." But is this really the case? Is it not, in fact, rather less than likely? We know at once that there are, minimally, two pigs, since one had roast beef (line 3) while another (line 4) did not and, concomitantly, that one went to the market while another stayed home. Both the juxtaposition of the two lines, emphasizing contrast (as well as the laws of logic) persuade us of the existence of at least two, separate, pigs. Moreover, it can be said with almost equal certainty that the pig having roast beef must be identified with either Pig One or Pig Two (otherwise we would have no thematic linkage between couplets)-although (and here is the great genius of the work) it is virtually impossible to say which! It is equally likely, for example, that the beef-eating pig got it at the market or raided his own refrigerator. In either case, the austere plaintiveness of line 4 assumes the non-beef-eating pig was somehow snookered. (Further, and on the level of historical criticism, the notion of five separate pigs, each undertaking a separate, lonely, existential action: going to market, eating roast beef or not, without any communication or interplay with one another strikes one as totally opposed to the complex spirit of the nursery rhyme genre.) Thus, it can be seen that, far from being self-evident, the existence of five pigs is nearly impossible, given the internal logic of the poem. Further than this, however, we plunge into muddy pigsties indeed. (As an aside, one can state without hesitation that pigs do not come in ones. Whenever you see one pig there is certain to be at least one more lurking nearby.) 
Certainly a case can be made for restricting completely the number of characters to the aforementioned two: the most likely scenario in this case being one who went to market (line 1), bought roast beef there (line 3) and returned home rejoicing (relying on the alternative reading of line 5: "Whee! Whee! Whee! / All the way home.")

Proponents of the three- and four-pig theories have depended primarily upon the traditional reading of line 5: "Wee, wee, wee!" which does seem to depict a single, separate pig, without either the security of home or the luxury of roast beef.

The problem with the three- and four-pig theses, of course, lies in the fact that each ignores the external toe evidence, while at the same time avoiding the attractive simplicity of the two-pig analysis. (In this respect, the four-pig analysis is even weaker than the three-pig version, which has, on its side, the traditional potency of the number three in folklore.) The three-pig theorists, who tend to hold traditional values, read the little pigs as members of a nuclear family-father going to market, mother staying home and the little one joining them later. On its side, however, the fourpig interpretation has relied strongly upon the metrical arrangement of the poem. It is noted that the first four lines each begin dactyllically in a counting off rhythm:

1. This little pig went to market

2. This little pig stayed home

3. This little pig had roast beef

4. This little pig had none

The tendency to associate each line with a separate pig is unavoidable. The fact, however, that the fifth line breaks out into a wild free verse form does not seem to me to thus refer back to a previously mentioned pig but rather to free the way for yet a new, more liberated pig. This however, brings us back to the five-pig hypothesis, which, as we have seen is poetically, philosophically, and morally untenable. (My own view, which may be obvious by now, is that the author deliberately left the number of pigs ambiguous.)

Leaving this issue, we should deal here with one aspect of the work which has hitherto gone unrecognized: the truly macabre features of the poem. The first line, charming as it is on one level, is chilling beneath the 
surface: "This little pig went to market." One gets a mental image of a jolly little pig trotting down a country road, wicker basket slung over one arm. But consider. How do pigs usually go to market? Crammed in the back of a pick-up truck with a bunch of other pigs, that's how. This possibility is rendered even more likely when we reflect that this pig is represented by the big toe - the largest and most marketable one, therefore. (The fact that the market mentioned could refer to the stock market opens an entirely new realm of possibility in both senses of the word "stock." Could we be dealing with a Yuppie, a young, upwardly mobile pig?) Another possibility, that the market referred to may be the Black Market, is very damaging to the three-pig hypothesis with its dependence upon traditional morality.

At any rate, the pig staying home (Pig Two) could well have been the one with the roast beef (table scraps) while the other (Pig One) has none. This reading, using the variant "Whee!" hints of a miraculous escape from the market.

A word should also be said about line 3. Do pigs eat roast beef - and if so, under what circumstances? Pigs are generally considered to eat anything, with scraps being the staple diet. Roast beef is a high quality scrap indeed, suitable only for pigs destined for the market in the macabre sense. With this in mind it is certainly not unreasonable to suppose that line 3 occurred chronologically before line 1 (as a flashback, perhaps) or, proleptically, that he was destined for the same role. The purposeful and delicate ambiguity here is inexhaustible, yet at the same time so subtle that many do not even notice it.

Another triumph of the poem is its versification. It should be noted at once that the first three lines can be made to scan either anapestically (truncating the first syllable for emphasis) or dactyllically, in a hypnotic, engulfing death-march. The proper scansion depends heavily upon the interpretation. In either case, however, the meter breaks into ecstatic spondees at the end of line 5, while line 6 completes the possibilities of English verse by dividing the dimeter into one trochaic and one iambic foot, respectively. So here, in six brief lines, the author has brought us drama, horror, mystery, delight, Dickinsonian slant rhyme, and an entire smorgasbord of metrical complexities. It is truly a wee, wee, wee poem containing all the "Whee, Whee, Whee!" of an epic. 